\title{
IDS40: Reflections from Across the Irish Sea
}

\section{Mary McKeown}

\begin{abstract}
1 The Dublin Roundtable
The IDS40 Roundtable meeting for Ireland was held in Dublin in April in conjunction with a conference at University College Dublin on Bridging Research and Policy on International Development: A New Role for Ireland. There are few Irish graduates of IDS, and fewer actually living in Ireland at the moment. It was interesting, therefore, to combine the Roundtable with a conference taking place already and thus bring in some different participants.
\end{abstract}

People at the conference had varying views on getting into discussions with IDS. One participant said, not entirely jokingly, 'I'm not giving IDS my ideas'. But that was only one participant; most others were generous and shared ideas enthusiastically.

Governance, security, investment, climate and the role of development studies were the main areas discussed. In many ways the ideas were predictable, but it was interesting for people to talk together about these things. Usually we just do not have the time to talk about 'ideas'.

\section{The conference}

I was fortunate to be able to come to IDS in September and participate in the anniversary conference. This meeting was interesting from several points of view. It was attended by people from outside IDS, the greater development and development research community. There were a lot of recognisable IDS people around, and the newer (to me) communications element was prominent. Definitely an enjoyable few days. And for me, a social event as well as a chance to contribute and to learn.

I am a practitioner, not a researcher. I use research and although I do not create it I have contributed from time to time. I am also old-fashioned enough to think that research should be useful. It should contribute to enabling people to live their lives to their fullest potential. Not everyone agrees, of course. Funds to carry out 'blue sky' research are seen as essential to a healthy research community. Discussions about the task of research were also interesting: should researchers carry out research which contributes, or research which promotes their institute and the researcher, or should they do research which can be funded easily? Not all these issues were addressed. But there was a deep moral consciousness underlying much of what was said at the conference, a desire to 'do good', at the same time, and those contributing managed not to be smug or self-congratulatory.

A conference process is always interesting. The three days were spread out thinly. I had to miss the middle day because of a work commitment, and so I missed Joanna Kerr's presentation and Tony Benn's appearance, both of which were big hits by all accounts. I missed unveiling the bus in memory of Hans Singer, and going for a walk with Mick Moore. But I did meet a lot of old friends and made a few new ones.

The big events for me were listening to Mike Edwards talking about solutions and Bill Easterly about responsibility. I have not been so challenged in a long time. They were both excited by what they had to say and they made me think.

Building on his latest book (The White Man's Burden, 2006) Easterly asked who is responsible. If no one is responsible change does not happen. He asked 'is the aid business working'? He was challenging, but on reflection his description of the aid business was troubling. The idea that the poor are trapped and that the aid business keeps them trapped and powerless is a bit passé. Yes, the very poorest can be seen just as victims, but increasingly governments in 
poor countries do have more say in how their aid money is spent (through direct budget support) and, yes, there is a long way to go, but progress is being made in this area.

Edwards talked about 'development' and social transformation, which is first? How do we look at these things, and are they the same? Do we create knowledge? Is research a product? Or should we (researchers) facilitate democracy? Should we engage in policy debates or political processes?

I think we should do both. The danger is that the think-tanks and research institutions remove themselves from reality so much that their research is no longer relevant and timely. Of course development action is only as focused and policy-oriented as the people in the frontline. If the underpaid, underresourced healthworker (for example) takes bribes and the police abuse women, it does not matter what the policy papers say, development is not working. This is also true for Poverty Reduction Strategy Papers and any speech a parliamentarian makes whether at home or in an international forum.

Research tells us what is happening now, or what has already occurred. We should be focusing on how to use that information to make decisions which can assist in policy delivery. There seemed to be an assumption at the conference that we do not believe that research leads directly to policy change. Of course it is naïve to believe in a direct link. However, without relevant, timely research, policy has nothing to base itself on, except 'hunches' and 'ideas' with no backup and no intellectual or moral clout. Research is important, and how it is disseminated is important too.

The visibility at the conference of the communications staff from IDS was interesting. The daily conference newsletter, reminding us who said what yesterday bombarded me with information I knew I could not absorb. At the same time, the discussion on the skills 'we' need as researchers was interesting. There is a place for the truly academic researchers, those who communicate only with a small group of like-minded people. But there is an increasing need for research ideas to be made useful to practitioners. Of course, research needs to be published in serious journals and books written by people who can prove what they said, but the message needs to 'get out there', or there is no message.

There was no real discussion on the gap between knowing and doing, the gap between research and doing something about it (development). I would have liked to have heard more on this, though some presenters did allude to it. The knowing-doing gap is defined in business, healthcare and many other disciplines, and I would have liked to have heard it discussed from a development perspective.

\section{Beyond research?}

I found it interesting that the conference focused on research without referring to teaching. As an active member of the alumni association, we realise that only the DPhil students are actually trained as researchers in IDS. Although the other students get some training in research methods, the emphasis is on practice. The MPhil and MA students leave IDS to go on to work as practitioners. We are consultants, advisers, managers, government officers, bilateral and multilateral aid officials and so on. Some go on to academia and research and teach and write for a living, but most of us read and act for a living - and I missed this perspective at the conference.

The issue of continuing professional education in a fractured, thinly spread profession needs to be addressed. As alumni, we hope we can continue to engage with IDS and thereby keep up-to-date. Talking with former IDS colleagues during the conference about 'what to read' was interesting. One former Fellow, now a professor elsewhere, said that he does not read Working Papers anymore, he does not have time to read unproven ideas. If he finds that, when he works in a thinking environment, what can the rest of us read to enhance our understanding and keep up with the issues of the day? How can we stay informed and effective? Through the years, the IDS Bulletin and other papers from IDS have been an important means for readers all over the world to keep in touch with the ideas emanating from the Institute - but the way we use and transfer knowledge is changing, as the proliferation of 'knowledge services' at IDS are one indication of the new ways people want to engage with research and use it in their work. 